\title{
4.
}

\section{The Paradigm of Game System Building}

\author{
Hartmut Koenitz \& Mirjam Palosaari Eladhari
}

Transactions of the Digital Games Research Association November 2021, Vol. 5 No 3, pp. 65-90. ISSN 2328-9422

(C) The text of this work is licensed under a Creative Commons Attribution - NonCommercial -NonDerivative 4.0 License (http://creativecommons.org/licenses/by-ncnd/ 2.5/).

IMAGES: All images appearing in this work are property of the respective copyright owners, and are not released into the Creative Commons. The respective owners reserve all rights

\section{ABSTRACT}

In this article, we posit 'game system building' as a paradigm for game design. Inspired by earlier perspectives on cybernetic art, and current practices in game development and education, we consider the creation of dynamic game systems as a creativeartistic practice where the consideration of complex and often unpredictable behavior and effects are as foundational as the individual elements (rules, graphics, characters, UI etc.) of a game. The paradigm of 'game system building' has important implications for the education of designers and games scholars. In this article, we introduce the paradigm and its lineage, and propose an educational approach that reflects 'game system building'. 
Keywords

game systems, game system building, artistic practice, pedagogy, education, cybernetics, complex systems

\section{INTRODUCTION: CREATING VIDEO GAMES}

Building games is an artistic creative practice that requires designers, artists and developers to acknowledge, accommodate and even embrace unpredictability that stems from a complex interplay of system and user actions. In games education, it is tempting to adopt a mechanistic view where we teach that making a game system is mainly about rules and causality, e.g., "if you do A, then B happens". However, this is an undue simplification, which does not fully reflect the actual practice in handling unpredictability. In this paper, we posit that it is critical to trust - from the very outset - that we and our students are capable of embracing the complexity of the game design space. We introduce game system building as a paradigm to express this aspect and help educators and students to fully make use of the unique and rich possibilities that are at our fingertips as creators and thinkers in the field of games.

Let us start by asking: What is the activity of creating video games? "Game design” might be our first answer. While this reply is correct, it is also incomplete. Do we design video games the same way we design a piece of furniture or a coffee maker? Intuitively, we might say 'no', as neither of these products are dynamic artifacts. With video games, a central concern is the creation of reactive artifacts that enable continuous engagement and feedback - what the game designer builds can best be described as a dynamic, reactive system. It is not a static artifact, a "product" in the sense of a well-made piece of furniture that serves its purpose without modification as long as it is used. Yet, it is also not simply a machine in the same way a coffee maker or a bicycle are functioning machines as a result of the combination of 
their parts. Instead, the totality of a game is more than the sum of its parts (rules, graphics, characters, UI etc.), and therefore, game design is concerned with how the elements interact and how players can use the resulting system. Game design might be best understood as 'game system building', a creative-artistic practice which foregrounds the consideration of complex and often unpredictable behavior that emerges out of the intricate combinatorics of dynamic systems with players' interactions. Indeed, many game designers and educators are keenly aware of this fact and certainly reflect it in their practice and teaching. However, published analytical and educational perspectives so far have not fully embraced this notion or put it in words. What we introduce here is a conceptual framing for a phenomenon that has been recognized for a while in the practice of game design and education.

In this article, we consider the status quo in game design and education from a conceptual perspective, develop the paradigm of game system building, outline its lineage from cybernetics, and discuss its implication for education in games programs.

\section{GAME STUDIES, GAME DESIGN AND EDUCATION}

Conceptually, game design exists in a space influenced by the interplay of theoretical frameworks developed in games studies, approaches that emerged in games education, and the pragmatics of game design practice. Early game studies focused on distinguishing the new discipline from the study of earlier mediated forms. During this period, ludology scholars frequently discussed the dynamic nature of games, and the empowered role of the player vs. reader. A common pattern in defining games and game design ever since has been to place a central emphasis on rules. For example, Markku Eskelinen defines the "gaming situation" as a "combination of ends, means, rules, equipment and manipulative action.” (Eskelinen 2001) Conversely, Espen Aarseth describes games as "simulations" based on "logical rules": 
Games, however, are often simulations; they are not static labyrinths like hypertexts or literary fictions. The simulation aspect is crucial: it is a radically different alternative to narratives as a cognitive and communicative structure. Simulations are bottom up; they are complex systems based on logical rules. (Aarseth 2001)

Equally, Jesper Juul takes the rule aspect as central:

"A game is a (1) rule-based formal system with a (2) variable and quantifiable outcome, where (3) different outcomes are assigned different values, (4) the player exerts effort in order to influence the outcome, (5) the player feels attached to the outcome, and (6) the consequences of the activity are optional and negotiable. (Juul, 2003)

While the definitions of games in the texts mentioned above differ in many aspects, rules are a shared feature and there is no doubt regarding their importance for games. Even more recently, the notion of rules was still taken as representational of the overall design intention of a game: “The goal of a game-for example 'supporting environmentalism' — can be found in its formal system, more specifically in the properties of the rules." (Raessens 2019)

Yet, the question remains whether rules provide a paradigm that holds as an overarching conceptual perspective on games. Game systems contain many additional elements - graphics, characters, narrative structures (for narrative-focused games), UI and procedural generation. Consequently, it might be better to understand rules as an essential ingredient, for example, as Jesse Schell does in The Art of Game Design: A Book of Lenses (2008), a book widely used in games teaching.

Rules, by themselves, are too limited as a paradigm for game creation and analysis. An insightful perspective in this regard comes from Michael Mateas and Andrew Stern (2005), who describe game design as an instance of "wicked problems" (cf. Rittel \& Weber 1973), where every attempt at solving a problem changes the very understanding of the problem. Mateas and Stern 
draw parallels to architecture, where the understanding of dependencies and affordances of various elements are a necessary ingredient for the creation of a building (building materials, statics, load on floors, the properties of the ground the building will stand on, energy requirements etc.). Transferring this understanding to game design means to take a wider view than commonly used, one that includes a consideration of the affordances of authoring tools like Unity and Unreal, but also the complex interplay of system and user actions and reactions in games (cf. discussions on “emergent gameplay” (Spector 2007, Lundgren et al. 2009, Fizek 2014)).

The limiting focus on rules might also be a factor that contributed to what can be understood as a rift between game theoreticians and game design educators. Many educators saw the ludology/ narratology debate as nothing more than an amusing storm in a teacup and considered the efforts at definitions at the dawn of games studies to have little relevance for practical education. Instead, many of them, especially in the late 1990s and early 2000s, focused on teaching students how to make games. Concretely, game education included aspects such as:

- Learn to make clean assets (2D, 3D, audio, dialog text).

- Write an if-clause.

- Learn to brainstorm and work together nicely and efficiently.

- Learn versioning.

The focus on basic and necessary aspects meant that students learned the craft because they wanted to create games. That is not a small feat, especially since familiarity with games through playing only goes so far. The shift from consumer to producer is radical, even more so as making games is a considerable challenge, requiring the combination of creative vision, technical knowledge, UI considerations, team management and marketing aspects - a truly multi-disciplinary effort. Specialized roles, similar to the 
many different crafts in the film industry, took years to develop and in some are areas that are still forming, e.g., the responsibilities of narrative designer vs. game writer, or the role of team members concerned with procedural content creation.

Yet, a purely practical perspective is limited in its ability to provide the reflection necessary to move beyond the replication and refinement of existing games, and lay the foundations for sustainable development and continued innovation in game design. Our conceptualization can serve as a basis for both the practice and an education that eclipses the merely technical and craft aspects. To demonstrate the shift in perspective, we will now consider Jose Zagal's education-focused framework in his book on Ludoliteracy (2010). Zagal here develops Gee's perspective on semiotic domains further in the context of games. Zagal starts with Gee's hierarchy of literacy:

1. Ability to decode.

2. Ability to understand meanings with respect to a semiotic domain.

3. Ability to produce meanings with respect to a semiotic domain.

He then re-interprets these categories for games literacy:

For games, being able to decode is thus analogous to being able to play. Gee's second element, understanding meanings with respect to a semiotic domain, becomes understanding meanings with respect to games, and the third, produce meanings with respect to a semiotic domain, can be expressed as the ability to make games. Thus, games literacy can be defined as:

1. Having the ability to play games.

2. Having the ability to understand meanings with respect to games.

3. Having the ability to make games. (Zagal 2010) 
While this perspective produces a neat segmentation and hierarchy for learning, it does not fully capture the requirement for active meaning-making with interactive forms like games, which produce meaning through playing. To cover this aspect, we posit a fourth category:

1. Ability to decode.

2. Ability to understand meanings with respect to a semiotic domain.

3. Ability to produce meanings with respect to a semiotic domain.

4. Ability to produce artifacts that engender meaningmaking by domain-literate others.

Or in more game-specific terms:

1. Having the ability to play games.

2. Having the ability to understand meanings with respect to games.

3. Having the ability to produce meanings while interacting with games.

4. Having the ability to make games as meaning-making devices for others.

Our emphasis on system building captures this enhanced understanding, that game making is the production of meaningmaking devices for others, the creation of artifacts whose meanings are never fully determined a priori by their creators.

What we are describing here is a shift from static objects to dynamic systems that constitute a challenge to many existing analytical frameworks (e.g., Lankoski \& Björk 2015a, Järvinen 2008). This challenge has been detected before (e.g., by Mateas and Stern, referenced above) and yet is still in need of continued attention. Put simply, frameworks originating in the analysis of 
static objects are limited in their ability to capture dynamic, systemic behavior. For example, in a book chapter on the formal analysis of games, Petri Lankoski and Staffan Björk discuss the scope of existing analytical frameworks and point out that these traditional frameworks cannot entirely describe complex game systems. Instead, formal analysis has to concentrate only on parts of games, essentially a vertical slice:

Many contemporary games are too big to be described as whole. For many purposes, first one needs to find a part of the game or parts of games that are analyzed. This requires building a rough understanding of the game by playing it and distinguishing the parts that are good candidates for analysis in terms of one's research questions. [our emphasis] (Lankoski \& Björk 2015b)

A variety of the same issue also exists in several practice-oriented books frequently used in games education, in that they do not fully embrace a systemic approach towards game design. While the term system is frequently mentioned, many books on the subject do not treat the problem of video game design as anything more than the sum of its mechanical parts, as exemplified by Salen and Zimmerman: "When understood in this way-as a set of parts that together form a complex whole-it is clear that games are systems." (2003, p. 50) The same publication even mentions uncertainty and cybernetics, but stops short of considering a systemic understanding. A chapter on Games as Systems of Uncertainty is concerned with randomness, exemplified by dice throwing and the uncertainty of play outcomes, not system behaviors. Conversely, another chapter on Games as Cybernetic Systems does portray cybernetics as yet another element in a mechanistic world. Additional examples in this regard include Koster's book, A Theory of Fun for Game Design (2004), Braithwaite and Schreiber's Challenges for Game Designers (2008) and Tracy Fullerton et al.'s Game Design Workshop (2004) as well as Schell's The Art of Game Design: A book of lenses (2008) and Andrew Rollings and Ernest Adams on Game Design (2003). Certainly, these books provide many important insights 
and valuable advice for practical development. Yet, a common trend emerges from these books - that game design is stuck in a mechanistic world view. In the next section we will discuss the limitations of mechanical thinking, and start to develop a model that is rooted in a systemic understanding.

\section{THE LIMITATIONS OF MECHANICAL THINKING}

In the practice of game design, we are used to thinking in terms of mechanics. Indeed, Brenda Romero (2009) proclaimed mechanics to be the message as the design intentions behind an influential series of games. Yet, the very idea of mechanics assumes a Newtonian world model in which all parts combine to form a whole as the sum of its parts. When in this mindset, we have to imagine that dynamics and aesthetics can be achieved as a function of the mechanics, exactly as Hunicke et al. have described it in their MDA model (2004), a conceptual framework influential in games education that considers game design as composed of mechanics, dynamics, and aesthetics. However, we know that the Newtonian way of considering the universe is not sufficient to explain the complex world around us - an insight reflected in the natural sciences at least since Einstein's Relativity theory (1916), further developed in quantum physics (maybe most famously in Schrödingers 'cat' thought experiment (1935)), and more generally applied in cybernetics (Wiener 1948) system theory (Bertalanffy 1969) as well as complexity theory (for an overview see Turner \& Baker 2019). The same is true for procedural and participatory game systems. Given the unpredictability that is introduced by unexpected combinatorics, co-creation by players and procedural content generation, we need to embrace more advanced models such as chaos theory (Alligood et al. 1997). Yet, to implement such a perspective in actual development is a considerable challenge. The standard way to think in mechanics is convenient and well established, yet the limitations of Newtonian thinking drives designers to assume a parallel mindset, a kind 
of 'doublethink' to accommodate the unpredictability of complex systems (Cummins 1999, Bossomaier \& Green 2000).

More concretely, MDA embeds the limitations of a Newtonian world view, in that a dynamic resulting from a mechanic is always predictable. Even when the combination space is vast, it would be predictable with enough computational brute force - analogous to Isaac Asimov's concept of psychohistory in the Foundation series (1951), a fictional work that was written pre-chaos theory. "Psychohistory" postulates that history is predictable in its entirety, provided enough computational capacity is available for the necessary calculations.

Indeed, if the game in question is a zero-sum game (e.g., a constant sum game, in which one person's gain is equivalent to another's loss, so the net change in benefit is zero), such as chess, then it *is* possible to calculate all possible outcomes of the movement of the pieces, if the search algorithm and the processing power allows it. However, when we consider the design of systems that include unpredictable elements, the concept of predictable dynamics as an effect of designed mechanics no longer holds (as, for example, has been observed in the real-world context of accident investigations (Dekker et al. 2011)). An example in this regard are systems that allow for user-created content that become part of the fictional world, especially if users are allowed to add their own executable code and macros. Even more complexity enters the picture when groups of players or users create and adapt their own ('house') rules for how the game can be played, something that is happening in most MMORPGs where player communities thrive, for example, in the ways groups of players act together in WoW (Blizzard Entertainment 2004). Different cultures develop on different servers, and cannot be predicted in a computational way, no matter how much computational power is thrown at it. Games with large numbers of players, and games where players are allowed to co-create, are subject to the effects of chaos theory, just as the real world. Yet, many games exhibit behavior that is unexpected and difficult to predict as the result of complex 
combinatorics and/or procedural generation - even without large player populations and user generated content. Consequently, mechanical thinking becomes an impediment for developers in their design work, since this paradigm assumes that the worlds they build will behave according to Newtonian law.

Mateas and Stern (2005) even argue that in order to fully understand a complex game-like system, it is necessary to build it, and furthermore, the act of building can facilitate the analysis of existing games. Their stance is one that resonates with much of the practice in current games education, where prototyping and game making is central. The act of building allows exploration of game design spaces. However, this perspective might also be unrealistic, as the time and effort for building is not always available, especially during the course of an educational program. Therefore, Mateas and Stern's method does not mitigate the need for a conceptual understanding of game systems and a paradigm of game system building.

Fundamentally, the game system builder designs for unpredictability. In order to capture this aspect of game design, we propose to shift the perspective, and talk about Architecture, Generation and Participation as foundational concepts in development. In the next section we will discuss the lineage of the system building paradigm from cybernetic art theory.

\section{GAME SYSTEM BUILDING AS A CREATIVE-ARTISTIC PRACTICE}

Our outset is that games are an art form, following Smuts (2005). While not all games can be considered 'art', some can be, just as in other forms, e.g., movies, pictures, and novels. As soon as we see games as art, the act of building them is an artistic practice. The term artistic practice refers to the ways in which an artist goes about their work. 
At this point, some remarks about the artistic status of games and game making as an artistic practice are in order. We are fully aware that talking about art in this context can be a double-edged sword. On the one hand, this is a strategic move that opens up a potentially productive connection to the discourse on artistic practice and computation (e.g., Penny 2000, Fleischmann \& Strauss 2006, Brinck 2007). On the other hand, there is the danger of getting bogged down in a distracting discussion on whether games can be art in principle and whether all games production can be understood as an artistic practice. Therefore, for the purpose of this paper, we want to clarify that our focus is on using the concept of "art practice" as a productive analogy for "game making”. Conversely, while we take the production of a game as an art practice on a more abstract level, we understand that not every role in the game production process can properly be called "artistic", since many sub-tasks might be better categorized as "creative”. This aspect is similar to film and theatre productions, where the overarching artistic process requires the output of creative work as building blocks. Therefore, in this paper, we regard game system building, the creation of an architecture containing rules and dynamic elements as a creative-artistic practice.

The notion of system building as the activity of artists can already be found in conceptualizations of cybernetic art practices during the latter half of the 20th century. Roy Ascott, a pioneer of cybernetic art, described it as follows:

A shift of human interest [...] from the thing, the object, the product to the process, the system, the event [...] (Ascott 1968)

What Ascott points out here is the difference to earlier forms of art like painting and sculpting, which are complete and determinate. We can understand these earlier forms as 'object art' in contrast to the "system art” Ascott is concerned with. He further explains:

I make structures in which the relationships of parts are not fixed and may be changed by the intervention of a spectator. [...] To project my ideas I set limits within which he may behave. [...] the participant 
becomes responsible for the extension of the artwork's meaning. (Ascott 1964)

The salient features of system art - the co-creative role of participants/players, and the dynamic and procedural nature of systems - have become even more accentuated by the development of video games in the decades that have passed. Consider, for example, No Mans Sky (Hello Games 2016), where players act in a procedurally generated universe that includes over 18 quintillion planets. Or, consider a social game world such as Second Life (Linden Lab 2003), which allows players to create their own environments in the world, and to write code that governs the behaviors of the objects players make.

\section{Unpredictability of Systems}

Ascott's change in perspective from object art to system art reflects the reality of game design work. Game designers cannot know with certainty how something they build, or create affordances for, will be used by players, and what results will come out of the combination of procedural elements and player interaction. Consequently, unpredictability is a fundamental element of the practice of building non-zero-sum game systems.

A pivotal question is therefore: How do we deal with this uncertainty as system building designers and game design educators? In the games industry, much effort is spent to accommodate the inherent uncertainty during the development of games. A common practice is to model system behavior around specific use cases. A more elaborate approach is to work with imagined users, or personas (Cooper 2004) who might want to play in a particular manner. The ultimate test of a game system is always with actual players - yet when we are still in the design phase of game production it is not possible to test with actual players, as the system is not realized yet. Common work-arounds are to use either paper mock-ups or simple digital prototypes. While these can demonstrate certain aspects of games, more 
complex game systems cannot be represented fully in such a way. Yet, even user testing with a feature-complete prototype cannot do much more than reduce the degree of uncertainty in game systems. This is the reason larger games require continued attention and software patches for a long time after initial release, even if best practices in software engineering and game design have been followed. A telling example is that of Microsoft's infamous twitter bot. Tay, which was intended to impersonate a nineteen-year-old American woman engaging in light conversation. The bot's utterances were, however, based on its 'learning' from the corpus of words that users were putting into the conversations with the chatbot. The result was that the chatbot was posting offensive and inflammatory text messages on Twitter (Wakefield 2016). Microsoft removed the bot within a matter of hours, not having been able to predict such an outcome.

In game education, while the importance of best practices and user testing has certainly been emphasized, there has not been an explicit concern with uncertainty. These challenges will not simply disappear when we move to a new paradigm of system building, but the changed perspective will enable us to understand uncertainty as an inherent aspect of system design, to plan for it in game design practice and to prepare students for this reality in game education. We will now introduce a model for creative system design, before discussing concrete approaches in education.

\section{A TRIPARTITE MODEL OF CREATIVE SYSTEM DESIGN}

As a starting point for a model of creative system design, we like to offer some conceptual framing. An important key to the artistic practice of game system building is to accept the fact that game systems will always entail unpredictability, even when sophisticated user testing methods or extensive run-time simulations are applied. It is helpful here to consider Cook's distinction between the generative space and the possibility space 
of systems (Cook 2019). The generative space of a procedurally created environment can be enormous: for example, there can be $64921,600,000,000,000,000$ different virtual landscapes instantiated in MineCraft (ibid). This number, albeit large, is finite and determined. In contrast, the possibility space of this system is even bigger, as it describes everything that players can create with MineCraft - and for this space there are no practical restrictions. On this basis, we propose a conceptual solution - to understand a game system as three connected layers, all of which need to be considered by the game system builder:

1. Architecture; creating the elements and relationships of a system (rules, characters, landscapes, objects, objectives, trajectories, etc.). The dynamic artifacts that serve as raw material for further processing.

2. Generation: computational co-creation - the systems when they are running, including procedural generation, and generative spaces.

3. Participation, performance, and co-creation of players in the possibility space - recognizing that play can also be considered as acts of artistic performance

This perspective demonstrates the challenge and pleasure of the practice of game system building - the challenge is in the fact that the output is an architecture, followed first by a layer of generation before the actual participatory engagement of the players happens. The pleasure is in the unfolding possibilities - a never ending number of 'what-ifs' being realized. Game design, as an artisticcreative practice, means to understand both the challenge to design for potentialities, and the pleasure of seeing them realized by players - even if these are engaged in activities that are not in line with the original intent ("transgressive play" (Aarseth 2007, Jorgensen \& Karlsen 2019)). 


\section{AN EDUCATION IN GAME SYSTEM BUILDING}

The move to the perspective of "system building" as a foundational post-Newtonian paradigm for game design (and related disciplines) has important implications for the education of designers and games scholars. We are proposing to make the understanding of game systems building a necessary element of game education.

Here, too, we can learn from Ascott. In the 1960s, he was faced with the educational challenge of teaching cybernetic art, essentially to train art students in systemic thinking and design, and to raise their awareness of the opportunities and limitations of technological developments. Ascott's response to this challenge was the development of a groundcourse at the Ealing College of Art, a two-year training program with a focus on challenging students' established perceptions of object art, and transform them into cybernetic artists with a systemic approach. A cornerstone of the educational program was the collaboration between artists and scientists. Through an ongoing series of challenges, students had to create solutions using artistic means (e.g., "Create a world on paper with major and minor structural systems. Show a fault occurring in the minor one; design a repair centre to put it right" (Ascott 1964)). They also collaborated with other students:

[The students] form groups of six. These sexagonal organisms, whose members are of necessity interdependent and highly conscious of each other's capabilities and limitations, are set the goal of producing out of substances and space in their environment, an ordered entity.

\section{$[\ldots .$.}

The subsequent "ordered entities" are as diverse as the composite personalities of the organisms they reflect. Totems, time machines, sense boxes, films, sexagonal cabinets, cages have been produced out of the flux of discussion and activity. (Ascott 1964) 
Ascott took inspiration for the groundcourse concept from the educational approach of the Bauhaus, arguably the most influential design school of the 20th century. Bauhaus founding director, Walter Gropius, saw the separation of specialized knowledge as a fundamental flaw of contemporary education in the early 20th century - for example that architects did not understand furniture making (the term "design” would become popular only later), or that the makers of daily use products, such as silverware and crockery, were separated from architecture. Conversely, he saw many traditional professional crafts such as carpentry as disconnected from developments in industrial manufacturing. Gropius' solution was the introduction of an integrated curriculum which started with the "Vorlehre" - a 'preliminary course' mandatory for all students, in which they acquired a shared foundation of basic knowledge in materials, color and form (Figure 1).
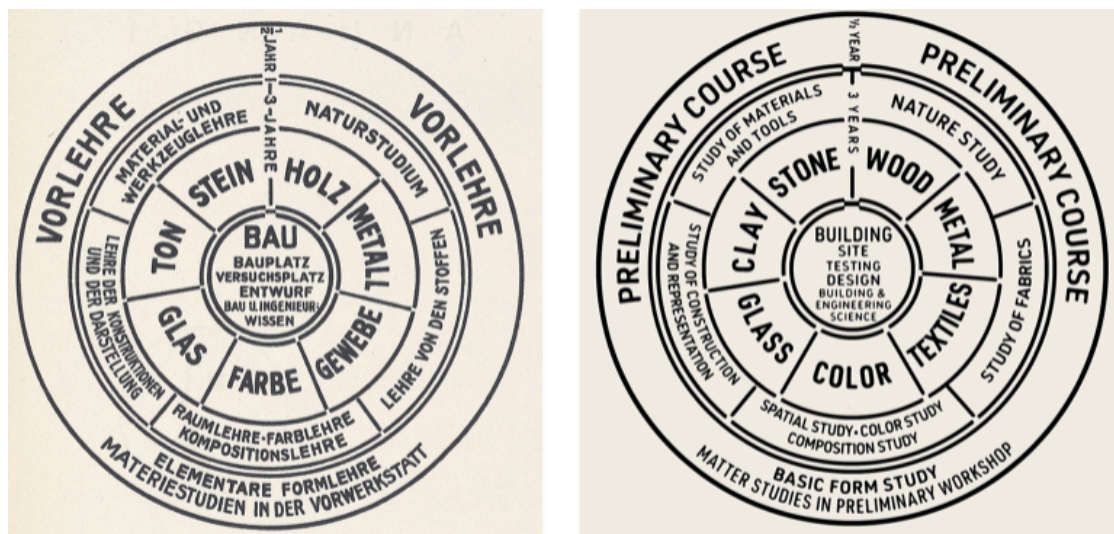

Figure 1: Diagram of initial Bauhaus curriculum (German original on the left, English translation on the right). "Vorlehre" (preliminary course) is the outer ring, followed by more specialized training in the inner rings that eventually come together in different aspects of building ("Bau”) Source: The Getty Research Institute

In games education, the idea of the groundcourse is practiced. There is a common awareness that people working in different roles on a game project must have fundamental knowledge about each other's expertise. A programmer cannot be effective without 
understanding computer graphics, a game artist needs to have basic programming and technical knowledge in order to create usable assets, and both need to understand the technical limitations and the opportunities of the technology in order to create fulfilling user experiences. Thus, in games education it is a common approach to start a longer education with courses that teach students fundamental concepts and skills together.

Yet, current approaches foreground a mechanistic perspective (the result is the sum of its parts) and not one that emphasizes systemic thinking (the elements together form a system with complex and often unpredictable behavior). The conceptual shift we propose would reorient existing groundcourses towards systemic understanding and the design of systems. This represents a particular challenge, as we have no existing metaphor for it. Everyday metaphors like "construction of a house" or "cooking" fail in communicating the meaning of complexity and unpredictability inherent in system building. This aspect is the pedagogical backdrop and reasoning for Ascott's seemingly 'wild' collaboration exercises, and why they still provide inspiration for a reorientation of games education towards system building.

In games education, such exercises could include observations of complex systems outside of games (e.g., factories and ecosystems), studies of games' systemic behavior, and the modification of an existing game (e.g., add a new feature and report on the unintended consequences you observe). To make this shift more concrete, in the following section, we propose a range of example projects for different educational setups.

\section{GAME SYSTEM BUILDING EXAMPLE PROJECTS}

\section{An Afternoon Workshop}

Design a paper-based game in which (un)happiness is spread like an infection, similar to the way coronavirus is spread. What unintended consequences could occur? 
Design a prototype in which there is a disconnect between the objective and your abilities. For instance, you need to pick something up, but your tool is too unwieldy and powerful for the fragile object you are required to pick up. Or the other way around; you are very weak and have to move a heavy object. What are the effects of this disconnect? What strategies can players use to succeed, regardless?

\section{Students Working for a Week}

What would robots cook for robots (or aliens or bats)? Design a supply system for this kind of food, and consider the occurrence of a supply scarcity (similar to a drought that causes a shortage in human food) and how the system would deal with it.

You wake up one morning to find that you are a sponge. How is your life now: what do you need, what is meaningful to you, and what does your new everyday life look like? What can you do, and what can be done to you? Design a world for yourself, your fellow sponges, and the other beings in the new environment.

\section{Students Working for Five Weeks}

Design a game that loses a feature (e.g., ability to zoom in or out, ability to carry supplies) every ten minutes, yet the objectives stay the same. Invite test players, and observe their reaction.

Design and explore the effects of an unreliable facial recognition system. Use it to keep a virtual machinery running by requiring verification at regular intervals. Consider what a failure to verify would mean to the machinery. Use a ready-made image recognition API, such as Amazon Rekognition or Google Cloud Vision, but randomly feed deteriorated images to it and observe the effects.

Create a prototype game in which the player character encounters regular personality changes, and observe how players react. 
Students working over the course of a multi-year program

\section{Iterative system re-design}

Each year, over the course of the educational program, have students revisit game systems they have designed. For example, in the first year of a three-year program, work with one of the suggested projects, as described above. In the second year, instruct the students to go back to the game from the first year to either add an additional system and integrate it with the existing one(s), or to completely exchange one system for a different one. Preserve the design intentions for the play experience. Have the students conduct and document play tests. In the third year, instruct the students to radically change the play experience of the game, while maintaining the system aspects of the game version they built in the second year. Have the students conduct, document and analyze data from their play tests, and have them compare the results with the results they gathered in the second year.

\section{Longitudinal multi-player world}

Design a multiplayer game world that explores the interaction between two or more different systems, for example, two different alien populations on a planet with conditions different from earth. Start with one population and then introduce the other one at a later stage. Have the two populations influence each other through their actions. The students should play each other's games over the whole length of the educational program to facilitate longitudinal studies of multiplayer game systems and the effect of design changes on them. Regularly perform user studies, and also evaluate technical aspects, such as code quality and sustainability. This setup would have the additional desired effect of solving the recruiting problem for the study of multiplayer games by enlisting students. 


\section{CONCLUSION}

In this paper, we have introduced 'game system building' as a paradigm for game design. We motivate this perspective through a discussion of the limitations of Newtonian mechanistic thinking, and argue for the need to embrace the systemic nature of games, which means to acknowledge complex behavior and often unpredictable effects. In addition, our perspective creates an opportunity for a productive dialog with system-related art practices, such as cybernetic art.

As a first step towards a more developed perspective of this paradigm, we propose a conceptual understanding of game system building as three connected layers of co-creation, all of which need to be considered by the game system designer: the architecture, the generation, and the participation.

Finally, we consider implications for education and suggest a change in focus for the common groundcourses in game design programs; a shift from a mechanistic perspective, where the result is the sum of its parts, towards an approach that considers systemic thinking and designing. To facilitate this change, we discuss a range of example projects for different educational setups.

Our future work will be the further development of the 'game system building' paradigm in concert with the game design community and games educators.

\section{BIBLIOGRAPHY}

Aarseth, E., 2001. Computer Game Studies, Year One. Game Studies, 1(1).

Aaseth, E., 2007. I Fought the Law: Transgressive Play and The Implied Player. In: Proceedings of the 2007 DiGRA International Conference: Situated Play. [online] The University of Tokyo. 
86 Hartmut Koenitz \& Mirjam Palosaari Eladhari

Available at: <http:/www.digra.org/wp-content/uploads/digitallibrary/07313.03489.pdf $>$.

Alligood, K.T. et al., 1997. Chaos: An introduction to dynamical systems. Physics Today, 50, p.67.

Ascott, R., 1964. The Construction of Change. Cambridge Opinion.

Ascott, R., 1968. The Cybernetic Stance: My Process and Purpose. Leonardo, 1(2), p.105.

Asimov, Isaac, 1951. Foundation. Foundation Series. United States: Gnome Press.

Bertalanffy, von, L., 1969. General System Theory, New York: George Braziller.

Blizzard Entertainment, 2004. World of Warcraft. [Virtual Game World].

Bossomaier, T.R.J. \& Green, D.G. (Eds.), 2000. Complex Systems, Cambridge, UK: Cambridge University Press.

Brathwaite, B. and Schreiber, I., 2008. Challenges for Game Designers. 1st ed. Charles River Media.

Brinck, I., 2007. Situated cognition, dynamic systems, and art: On artistic creativity and aesthetic experience.

Cook, M., 2019. Tutorial: Generative \& Possibility Space,

Cooper, A. 2004. The inmates are running the asylum: [Why hightech products drive us crazy and how to restore the sanity], Sams Indianapolis.

Cummins, J., 1999. The ethics of doublethink: Language rights and the bilingual education debate. TESOL journal, 8(3), pp.13-17. 
Dekker, S., Cilliers, P. \& Hofmeyr, J.-H., 2011. The complexity of failure: Implications of complexity theory for safety investigations. Safety Science, 49(6), pp.939-945.

Einstein, A., 1916. Die Grundlage der allgemeinen Relativitätstheorie. Analen der Physik, 49(7). Leipzig

Eskelinen, M., 2001. The gaming situation. Game Studies, 1(1). Available at: http://www.gamestudies.org/0101/eskelinen/.

Fizek, S., 2014. Why fun matters: in search of emergent playful experiences. In Fuchs, M., Fizek, S., Ruffino, P., Schrape, N. (eds.) Rethinking gamification (pp. 273-287). meson press.

Fleischmann, M. and Strauss, W., 2006. Public Space of Knowledge-Artistic Practice in Aesthetic Computing. Aesthetic Computing. MIT Press, Cambridge.

Fullerton, T., Swain, C. and Hoffman, S., 2004. Game Design Workshop: Designing, Prototyping, and Playtesting Games. CMP Books.

Hello Games, 2016. No Man’s Sky. (Video Game.)

Hunicke, R., LeBlanc, M. \& Zubek, R., 2004. MDA: A Formal Approach to Game Design and Game Research, AAAI Press.

Järvinen, A., 2008. Games without frontiers: Theories and methods for game studies and design. Tampere University Press.

Jorgensen, K., \& Karlsen, F. (Eds.). (2019). Transgression in Games and Play. MIT Press.

Juul, J., 2003. The Game, the Player, the World: Looking for a Heart of Gameness. Level Up: Digital Games Research Conference Proceedings. M. Copier and J. Raessens. Utrecht, Utrecht University, pp. 30-45 
Koster, R., 2004. A Theory of Fun for Game Design. 1st ed. Paraglyph Press.

Lankoski, P. \& Björk, S., 2015a. Game Research Methods: An Overview, ETC Press

Lankoski, P. \& Björk, S., 2015b. Formal Analysis of Gameplay. In Game Research Methods: An Overview. ETC Press, pp. 23-35.

Lundgren, S., Bergström, K. and Björk, S., 2009, September. Exploring Aesthetic Ideals of Gameplay. In DiGRA Conference.

Linden Lab, 2003. Second Life, Linden Research, Inc [Virtual Social World].

Mateas, M. and Stern, A., 2005. Build It to Understand It: Ludology Meets Narratology in Game Design Space. In: DiGRA '05 - Proceedings of the 2005 DiGRA International Conference: Changing Views: Worlds in Play. Vancouver, Canada.

Penny, S., 2000. Agents as artworks and agent design as artistic practice. Human cognition and social agent technology, pp.395-414.

Raessens, J., 2018. Collapsus, or how to make players become ecological citizens. In The Playful Citizen. Games and Play, pp. $1-30$.

Rittel, H. and Webber, M., 1973. Dilemmas in a General Theory of Planning. Elsevier Scientific Publishing.

Rollings, A. and Adams, E., 2003. On Game Design. 1st ed. Indianapolis, Ind: New Riders.

Romero (formerly Brathwaite), B., 2009. The Mechanic is the Message. Available at: $<$ https://mechanicmessage.wordpress.com> [Accessed 2 Apr. 2020]. 
Salen, K. and Zimmerman, E., 2003. Rules of Play: Game Design Fundamentals. MIT Press.

Schell, J., 2008. The Art of Game Design: A book of lenses. 1st ed. Morgan Kaufmann.

Schrödinger, E., 1935. Die Gegenwärtige Situation in der Quantenmechanik. Die Naturwissenschaften, 48(807).

Smuts, A., 2005. Are Video Games Art? Contemporary Aesthetics, 3.

Spector, W., 2007, August. Emergent gameplay: potential, pitfalls and progress. In Proceedings of the 2007 ACM SIGGRAPH symposium on Video games (pp. 7-7).

Turner, J.R. \& Baker, R.M., 2019. Complexity Theory: An Overview with Potential Applications for the Social Sciences. Systems, 7(1).

Wakefield, J., 2016. Microsoft chatbot is taught to swear on Twitter. [online] BBC News. Available at: <https://www.bbc.com/ news/technology-35890188> [Accessed 2 Apr. 2020].

Wiener, N., 1948. Cybernetics Or Control and Communication in the Animal and the Machine, MIT Press.

Zagal, J.P., 2010. Ludoliteracy Defining Understanding and Supporting Games Education, Pittsburgh, PA: ETC Press. 